\title{
Investigation of Violence Against Children in Schools with Types and Related Variables: Kosovo Sample
}

Armen Mustafa ${ }^{1}$

\begin{abstract}
The main purpose of this study was to conduct an investigation on the level (extent) of violence against children in school, on types of violence and on the relationship between violence and demographic characteristics of children (gender, residence and age). This study focused on a sample group of 618 children, respectively students of grades 10 to 12 of higher secondary schools in Prishtina, Kosovo. With this sample group a structured questionnaire applied, which was composed of four (4) questions for each of the following types of violence: violence against the property of children and school property, psychological violence, physical violence and sexual violence. Results of this study have shown that approximately $87 \%$ of children have experienced, at least, once one type of violence throughout their education. Among these types of violence, violence against the property of children and against school property has been reported the most $(73.6 \%)$, which is followed by psychological violence $(69.3 \%)$, then physical violence (47.5\%) and sexual violence (22.1\%). Data have shown that in the level of reliability $\alpha=$ 0.5 , gender as a demographic factor has appeared to be more influential in the prevalence of some types of violence (violence against property, psychological violence and physical violence), residence has appeared to be influential when speaking about physical violence only, while age has been shown to be an influential factor in the prevalence of violence against children in school.
\end{abstract}

Keywords: Violence against children, school, violence against property, psychological violence, physical violence and sexual violence.

\section{INTRODUCTION}

Violence against children is one of the main concerns in the agendas of international institutions and not only, due to the importance has this group of population for the future of every society. Taking into account this aspect and circumstances Kosovo society has gone through (such as war, etc.), which have left their traces behind, all this in a way is portraying today's social context, which is considerably, characterized with the presence of violence. These traces are even more sustainable, as they do rely on traditional aspects, according to which, violence is still considered a method for children education and discipline.

Therefore, such a social context is not only a suitable terrain to exercise the violence against children, but it is also justified, not only by the adults but also by the children themselves, accepting this as a social 'norm'. All this, is reflected in the 'practical' aspect of life as well, as there are, almost, no days when the part of daily news are not composed of chronicles treating topics of general violence, particularly the violence exercised against children, in certain cases with fatal consequences.

1 PhD, AAB College, Prishtina, Kosovo, armenmustafa@gmail.com 
Unfortunately, such a social "norm" is quite present in the institutions such as schools, which in fact have the duty to fight (tackle) the social norms that are in contradiction with the human rights and to support the aims (goals) of Kosovo country for a 'non-violent society' in accordance with human rights.

School is a place of a social, economic and cultural diversity, where children create the most diverse experiences with their peers, teachers and other school staff and with other persons who are frequenting the school for other purposes. Due to these facts, although the school is an educational institution and is supposed to be a safe environment, still the risk for the children to be exposed to the violence is very high. This, also for the fact that children spent most of their time in school and its surroundings.

In the UN Report on the Violence Against Children, when it comes to violence against children in schools, it is highlighted that the psychological and physical violence are the most frequent forms of violence exercised against students, with special emphasis on corporal punishments and other humiliating treatments, sexual violence and bullying (Pinheiro, 2006), harassment, threatening and physical assaults (Wall, 2004). In the UN Report we see that in many countries of the World (Egypt, other African countries and countries of Oceania) corporal, physical and psychological punishments are practices that are used by teachers to punish students for poor academic performance. In some US countries (23 of them), as in many other countries, corporal punishment is still in force. Unlike these countries, in Kosovo, the corporal punishment in schools, with all its forms, is strictly prohibited by the Law on Pre-University Education, although it is still being used as a 'social norm'. The use of physical and corporal punishment as one of the most spread forms of violence exercised by teachers against children in schools is mentioned by Seitz (2011) whereas Denmark, Krauss, Wesner, Midlarsky, and Gielen (2005) points out that the students often report the aggression, mockery, humiliation, unjust punishments, verbal abuse and even physical abuse which is exercised by teachers. While Currie et al (2004) in an international study of WHO, which was conducted in developed countries and countries under transition of Central and Eastern Europe, concluded that an average of $35 \%$ of students had been bullied during the last two months, with a percentage ranging from $15 \%$ in Sweden, up to $64 \%$ in Lithuania, comparing to the number of children who during the last 12 months had been involved in fights and physical violence, which is ranging from $25 \%$ in Finland up to $49 \%$ in Lithuania. Percentage of girls and boys involved in harassment acts is almost the same, whereas regarding the age of students, harassment is reduced with the age of children. In addition to the forms of physical violence and of harassments to which children in school and in community are exposed to (O'Keefe, 1997), violence against the property of children and its damage are mentioned as well as a widespread form of violence against children in school (Hyman, 1998; Kingery, Coggeshal, Alford, 1998). In general, various studies have shown that the violence against children, including the sexual violence, is exercised most often by peers and by teachers and other school staff members as well (Benbenishty and Astor, 2005; Pinheiro, 2006).

UN Report on the Violence against Children and other studies as well show that there are differences regarding the prevalence of violence and regarding the demographic characteristics of children. Boys are usually those who experience more physical violence (Pinhero, 2006; Currie, et al, 2004; O'Keefe, 1997), whereas girls are more exposed to sexual harassment and sexual violence (Pinheiro, 2006) and less endangered by non-sexual forms of violence (Kingery, Coggeshal and Alford, 1998). In the studies where the age appears to be influential in the prevalence of violence it turns out that the greater the age 
the smaller the victimization of children is (Benbenishty and Astor, 2005; Currie, C., Roberts, C., et al., 2004). Living in urban or rural areas may also result with an impact on the prevalence of violence against children. Students who are living in urban areas are more vulnerable to serious violent crimes (14 out of 1000 students), comparing to the students who are living in suburban areas (8 out of 1000) and other students living in rural parts (4 out of 1000) (Kaufman et al. 1998, 1999, 2000,200, cited in Tait, 2004, p. 117).

Also, the studies that have been carried out in Kosovo regarding the violence against children in schools have roughly come to similar conclusions. According to the Office of UNICEF in Kosovo (2004), "Violent discipline by punishing the children is present and an acceptable practice both at home and at schools, whereas the most frequent exercisers of violence are the close relatives home, teachers and peers in school, whereas peers on the way to school". While in a research that has been conducted by Save the Children (Krasniqi \& Osmani, 2012), approximately 85.9\% of children have reported about the violence experienced in schools, where the most common form is the form of physical violence. This violence, according to the children (respondents), is most commonly exercised by children themselves and by school teachers and principals".

The main purpose of this study is to investigate the level (extent) of violence against children in school, the types of violence as well as the relationship between violence and demographic characteristics of children (gender, residence and age).

\section{METHOD}

The main purpose of this study is to investigate the level (extent) of violence against children in school, the types of violence as well as the relationship between violence and demographic characteristics of children (gender, residence and age). This study is based on quantitative methodology. Survey was conducted with a sample group of 618 children, students of grades 10 - 12 from (ten) 10 higher secondary schools of Prishtina. Sample selection has been based on random simple probability sampling method, based on the level of confidence of $95 \%$ and the margin of errors of $5 \%$. With this sample was administered the questionnaire, which has aimed the collection of experiences of children about the violence in schools, through the self-reporting. Definition of violence against children is based on UN Report on Violence against Children (Pinheiro, 2006). According to this report, when we speak about violence in school we have to deal with physical violence, psychological violence and sexual violence. These three types of violence are supplemented with the fourth type of violence, namely violence against the property of children or violence on school property, based on the Instrument "The Juvenile Victimisation Questionnaire" (Hamby, Finkelhor, Ormrod, \& Turner, 2005). Questionnaire includes closed-ended questions, divided into four (4) parts: based on four (4) types of violence and four (4) questions are posed for each type of violence.

Part I. Violence against the property of children and violence on school property, which is used by children, such as: Damage and destruction of school property (chairs, desks, etc.) that are used by children; Damage and destruction of personal belongings (books, notebooks, backpacks, etc.); theft of personal belongings (money, pens, notebooks, etc.)' and robbery (taking by force) of personal belonging (money, backpacks, etc.). 
Part II. Physical violence: Hitting, kicking, punching, etc.: Pushing, pinching, grabbing by throat in school; Physical injuries from beatings or strikes; physical assault through the use of strong tools or firearms,

Part III. Psychological violence (insults, mockery, use of despicable names; anger, isolation from the others; verbal threats and intimidations, threats and intimidations through the use of weapons) and

Part IV. Sexual violence (verbal harassments and disturbances regarding the sexuality of the children, touching the body or intimate parts of the child without his/her consent; conditioning or forcing them to do or watch sexual things, as well as the sexual assault, attempted sexual violence or even sexual violence).

To apply the questionnaire, subjects (respondents) have been initially informed about the purpose and the consent was obtained by both, the respondents and the institutions (schools), where the questionnaire has been administered. The administration of questionnaire was done within a 40 minutes timeframe and afterwards the data from the questionnaire have been introduced and analysed through SPSS 22.

\section{FINDINGS}

\section{a. Prevalence of violence against children in school and its types}

Generally speaking $87 \%$ of participants in this research have at least once suffered (experienced) a type of violence in school during their education. Of all the forms of violence in school, violence against the property of children and the property of school was reported the most. It has actually been reported by $73.6 \%$ of the participants in the research. Violence against property was immediately followed by psychological violence with $69.3 \%$, then physical violence with $47.5 \%$ and sexual violence reported by $22.1 \%$ of the participants in the research. 


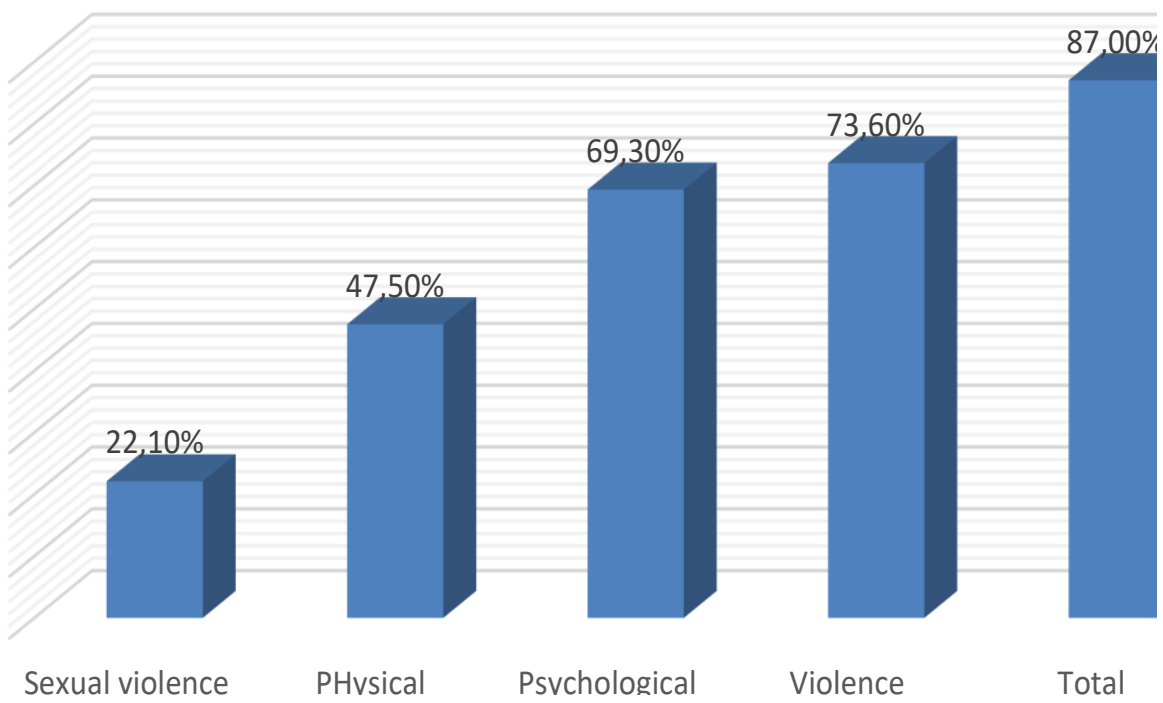

Figure 1. Violence Prevalence against Children at School $(\mathrm{N}=618)$

\section{b. Relationship between violence against children in school and their demographic characteristics}

Based on the data that have been tested in accordance with Kolmogorov - Smirnov test, it was showed that there was no normal distribution $(p=.000<\alpha=.05)$. In order to see the relationship between the violence against children in school and their demographic data, non-parametric tests Mann Whitney - U and Kruskall Wallis - H have been used, based on the level of confidence $\alpha=0.05$, which tests are equivalent of parametric Independent Samples t-Test and One Way Anova .

Table 1.

Mann Whitney test - the Relationship between the Types of Violence and Gender

\begin{tabular}{|c|c|c|c|c|c|c|}
\hline Types of violence & Gender & $\mathrm{N}$ & Mean Rank & Sum of Ranks & $\mathrm{U}$ & Sig. \\
\hline Psychological & $\mathrm{M}$ & 290 & 285.21 & 82711.5 & \multirow[b]{2}{*}{40516.5} & \multirow[b]{2}{*}{.017} \\
\hline violence & $\mathrm{W}$ & 309 & 313.88 & 96988.5 & & \\
\hline Violence against & M & 292 & 286.89 & 83770.5 & \multirow[b]{2}{*}{40992.5} & \multirow[b]{2}{*}{.017} \\
\hline the property & $\mathrm{W}$ & 310 & 315.27 & 97732.5 & & \\
\hline Physical & M & 298 & 319.22 & 95129.0 & \multirow{2}{*}{42398.0} & \multirow{2}{*}{.032} \\
\hline violence & $\mathrm{W}$ & 312 & 292.39 & 91226.0 & & \\
\hline Sexual & $\mathrm{M}$ & 297 & 312.49 & 92809.5 & \multirow[t]{2}{*}{44107.5} & \multirow[t]{2}{*}{.156} \\
\hline violence & $\mathrm{W}$ & 312 & 297.87 & 92935.5 & & \\
\hline
\end{tabular}


In order to see whether there are statistical differences in terms of gender and the various types of violence in school, we have referred to Mann- Whitney test. Test has shown that there are statistically significant differences between girls and boys in terms of the level of different types of violence experienced by them in school. When we speak about psychological violence, it appears that $U=40516.5$, $p=0.017<\alpha=0.5$, which means that there are differences between boys and girls regarding the level of the psychological violence sustained in school. If we refer to the Mean Rank, we see that the girls are the ones against whom the psychological violence is exercised the most in school (Mean Rank $=313.88$ ), comparing to the boys (Mean Rank $=285.21$ ).

The same can be said when we speak about the violence against the property of the students. Even with this type of violence, girls are those who have suffered more violence (Mean Rank $=315.27$ ), comparing to the boys (286.89). This gender difference from the statistical test appears to be significant in the statistical aspect $(\mathrm{U}=40992.5, p=0.017<\alpha=0.5)$, a result which indicates that the level of violence against property depends from the gender aspects of the children.

Difference between girls and boys appears to be statistically significant even in terms of physical violence $(\mathrm{U}=42398, p=.032<\alpha=0.5)$. Ranking table shows that when speaking about physical violence, boys are those who have a higher Mean Rank (319.22), comparing to the girls (292.39). Even in this case we can say that there are differences between boys and girls in terms of physical violence that has been suffered.

Differences between boys and girls are existing in terms of sexual violence in school as well, if we refer to the Mean Rank ( $F=297.87 \& M=312.49$ ), but this existing difference between them in terms of sexual violence, appears to be not statistically significant $(\mathrm{U}=44107.5, z=-1.419, p=.156>\alpha=0.5)$. So, there are no gender differences in terms of sexual violence.

Table 2.

Mann Whitney Test - the Relationship between the Types of Violence and Residence (Urban - Rural)

\begin{tabular}{|c|c|c|c|c|c|c|}
\hline Types of violence & Residence & $\mathrm{N}$ & Mean Rank & Sum of Ranks & $\mathrm{U}$ & Sig. \\
\hline Psychological & $\mathrm{U}$ & 471 & 300.87 & 141709.5 & \multirow[b]{2}{*}{29734.5} & \multirow[b]{2}{*}{.781} \\
\hline & $\mathrm{R}$ & 128 & 296.80 & 37990.5 & & \\
\hline Violence against & $\mathrm{U}$ & 474 & 305.61 & 144858.0 & \multirow[b]{2}{*}{28389.0} & \multirow[b]{2}{*}{.184} \\
\hline & $\mathrm{R}$ & 128 & 286.29 & 36645.0 & & \\
\hline Physical & $\mathrm{U}$ & 480 & 312.12 & 149819.0 & \multirow{2}{*}{28021.0} & \multirow{2}{*}{.042} \\
\hline violence & $\mathrm{R}$ & 130 & 281.05 & 36536.0 & & \\
\hline Sexual & $\mathrm{U}$ & 480 & 306.51 & 147126.0 & \multirow{2}{*}{44107.5} & \multirow{2}{*}{.156} \\
\hline violence & $\mathrm{R}$ & 129 & 299.37 & 38619.0 & & \\
\hline
\end{tabular}


When dealing with the relationship between violence against children in school and the residence, the Mean Rank shows that there is a difference regarding the level of violence experienced by the children coming from the rural areas and the children coming from urban areas However, in terms of psychological violence $(\mathrm{U}=29734.5, z=-.278, p=.781>\alpha=0.5)$; violence against property $(\mathrm{U}=28389.0, p=$ $.184>\alpha=0.5)$ and sexual violence $(\mathrm{U}=30234.0, p=.571>\alpha=0.5)$, these differences appear to be not statistically significant, which means that the psychological violence, violence against property and sexual violence against children in school are not influenced by whether the children come from the rural or urban areas.

But this cannot be said for the physical violence, where differences between children coming from urban areas (Mean Rank $=312.12$ ) and those coming from rural areas (281.05), appear to be statistically significant ( $\mathrm{U}=28021.0, p=.042<\alpha=0.5)$, which means that the level of physical violence is affected by whether the child is coming from rural or urban areas.

\section{Table 3.}

Kruskal Wallis - H Sample Reporting - The relationship between the types of violence and age

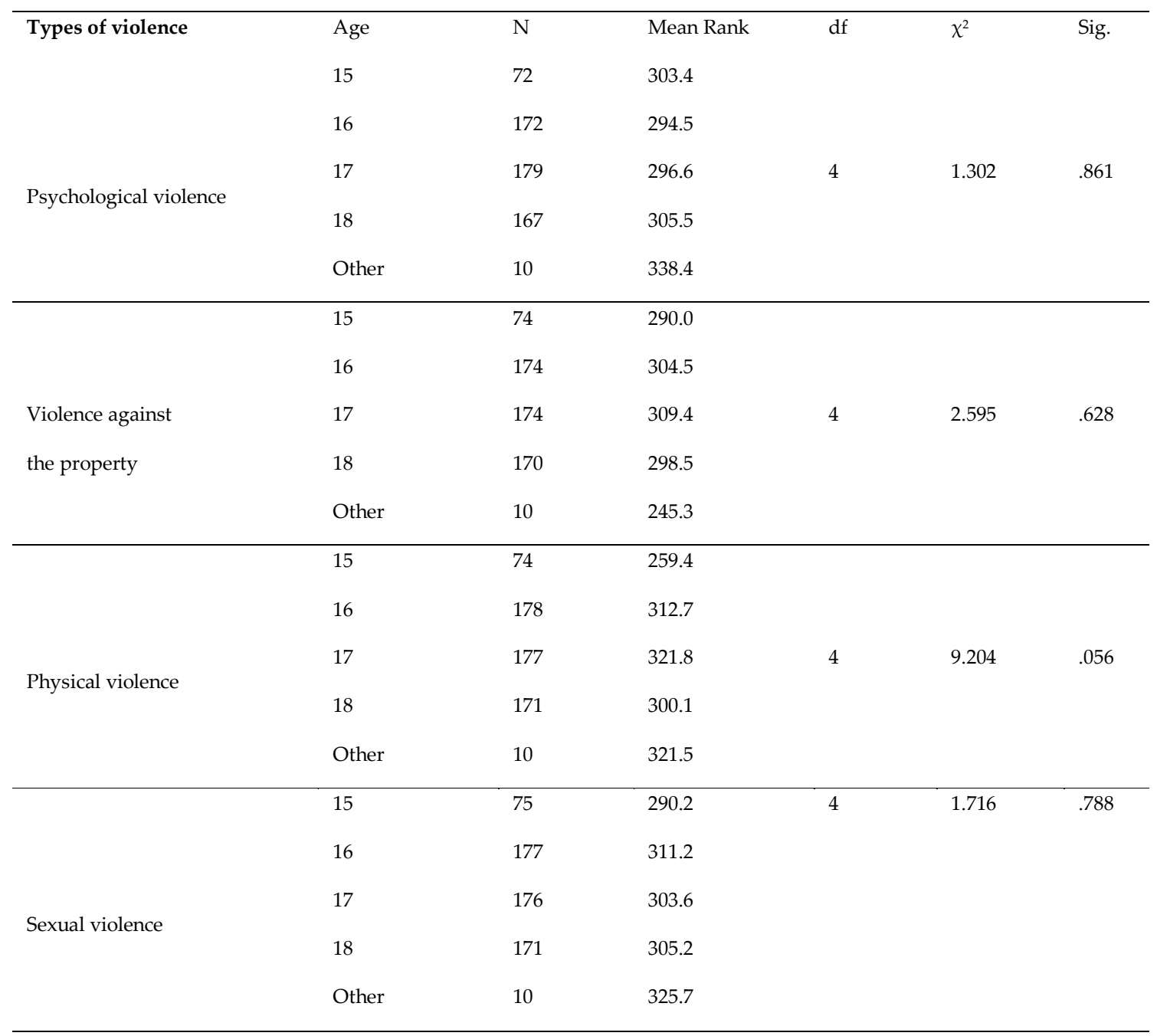


On the other hand, the age of children appears not to have a statistically valid impact in the prevalence of any type of violence against children in school. Statistical test Kruskal Wallis shows that there are no significant statistical differences between psychological violence and age (Chi-Square $(\chi)^{2}(\mathrm{df}=4, n=599)$ $=1.302, \mathrm{p}=0.861>\alpha=0.05)$; violence against property and age (Chi-Square $(\chi)^{2}(d f=4, n=602)=2.595, p=$ $0.628>\alpha=0.05)$; physical violence and age (Chi Square $\left.(\chi)^{2}(\mathrm{df}=4, n=610)=9.204, p=0.056>\alpha=0.05\right)$ and sexual violence and age (Chi-Square $\left.(\chi)^{2}(\mathrm{df}=4, n=609)=1.716, p=0.788>\alpha=0.05\right)$. Based on this, we can conclude that the prevalence of types of violence in school is not influenced from the age of children who have taken part in the research.

\section{RESULT and DISCUSSION}

Schools and educational settings are considered to be safe environments for children and for their welfare. However this study has shown that nine (9) out of ten (10) students $(87 \%)$ have, at least once, experienced the violence, exerted by the others, in school.

The study has also shown that out of the grouped types of violence used against teenagers in schools, violence which is related to the property of children and property of school is the one which is exercised the most. Approximately three (3) out of four (4) children, respectively $73.6 \%$ of them, have reported to have experienced such type of violence at least once during their education. It is followed by psychological violence, which has been reported by two (2) out of three (3) children (69.3\%), physical violence during the education has been reported by approximately half of the children who have taken part in the research (47.5\%) and sexual violence has been reported by more than one (1) out of five (5) children $(22.1 \%)$.

If we generalize the results of the violence against children in school, we can say that, it is a practice, which is present in Kosovar schools whether as a form of discipline of children in school or as a form of solving the problems between the children themselves, without excluding some abusive forms of apparent sexual violence. This violence has been experienced either directly, through a physical or a verbal contact or indirectly, such as violence against property.

Results of this study are supported by other studies. It means that the violence against the property and the psychological violence, as the most reported forms of violence, are supported by other studies (Hyman and Perone,1998; Kingery et al, 1998), whereas some other studies have emphasized the fact that the physical violence is the most experienced violence by children in school (Pinheiro, 2006; Tamo \& Karaj, 2006; UNICEF, 2005).

Even if we refer to the statistical figures of crime in Kosovo (Kosovo Police, 2015), we can see that the crimes against property are dominant, which then are followed by the crimes against human body and life. This may, in some way make our society more tolerant towards the violence against the property and less tolerant towards the interpersonal violence, especially physical and sexual violence.

On the other hand, some of the demographic factors appeared to have influenced the prevalence of violence against children in school, particularly in some types of violence. In this regard, gender has generally resulted to be more influential in the prevalence of some types of violence, respectively girls have mainly reported more about the psychological violence and violence against property, unlike boys 
who have reported more about the physical violence. Such a relationship may be explained up to a certain extent with gender roles (Pinheiro, 2006), that are emphasized in our society as well, according to which girls are considered to be physically weak and therefore more suitable for bullying and for various psychological pressures. On the other hand, boys are more preferred for physical confrontations and physical "solution" of problems.

Residence as a demographic factor has appeared to have a significant meaning in this relationship when speaking about physical violence, respectively children from town are those who report more about violence, especially physical violence. This in a way shows that in the environments where the life is more dynamic, where the structure of population is more heterogeneous and where the density of population is higher, the social control is missing and therefore the situational factors can be easily expressed (Salzinger, 2002). On the other hand, the age of participants in the study generally did not result in any meaningful relation in the prevalence of violence against children in school and this in a way is related to the fact that the participants of this study are relatively of the same school level (grades 10-12), which means that they are going through the same experiences speaking generally.

This study on violence against children in schools has its own limitations, which may have an impact on generalizations. One of such limitation is related with sample selection. The fact that the study sample is selected only from children aged 15-18, who come only from Pristina schools has its effect that the results cannot be generalized for children of other ages and for those coming from other areas of Kosovo.

The other limitation is related to the methodology, namely the use only of quantitative methods. The results would be more complete if quantitative data would be combined with qualitative data through interviews, focus groups or even through the use of other qualitative methods. However, these limitations do not reduce the value of the study, since the sample selection was based on strongly criteria of random probability sampling method based on the level of confidence of $95 \%$ and the margin of errors of $5 \%$ that has enabled us obtaining reilable and representative results for the target population.

Based on research findings that show a high level of violence against children in school, in spite of the fact that some of the variables did not have an impact on the types of violence that children have experienced in school, we have proposed a number of recommendations, which are mainly addressed at the institutional level and policy-making for protection against violence.

$\checkmark$ Development and adaptation of anti-violence education programs through the use of alternative non-violent methods of communication, negotiation, conflict resolution and positive discipline. These school programs can be offered within curricular and non-curricular activities.

$\checkmark \quad$ Schools should develop action plans to create schools as safe and friendly environments. In the development and implementation of the action plan, special attention should be paid to the involvement of students, parents and the community. Within the action plan, schools should provide management. 
$\checkmark \quad$ Establishment of multi professional teams in schools such with psychologists, social workers and other professionals. These teams would be a great help to children and others, to overcome the difficulties they have.

$\checkmark \quad$ Learning curricula should address social norms and prejudices that promote the use of violence against children, including gender and social prejudices, and promote equality, children's rights and social inclusion.

\section{REFERENCES}

Benbenishty, R., \& Astor, R. A. (2005). School violence in context: Culture, neighbourhood, family, school and gender. New York, Oxford University Press Inc.

Currie, C., Roberts, C., Morgan, A., Smith, R., Settertobulte, W., Samdal, O., \& Barnekow Rasmussen, V. (2004). Young people's health in context. Health Behaviour in School-aged Children (HBSC) study: International report from the 2001/2002 survey. Copenhagen, WHO Regional Office for Europe.

Denmark, F., Krauss, H. H., Wesner, R. W., Midlarsky, E., \& Gielen U. P. (2005). Violence in schools. crossnational and cross-cultural perspectives. New York, Springer Science+Business Media, Inc.

Hamby, S. L., Finkelhor, D., Ormrod, R., \& Turner, H. (2005). The Juvenile Victimization Questionnaire (JVQ): Administration and scoring manual. Durham, NH: Crimes against Children Research Center. Retrieved from http://www.unh.edu/ccrc/pdf/jvq/CV55newedition04.pdf.

Hyman, I. A., \& Perone, D. C. (1998). The other side of school violence: educator policies and practices that may contribute to student misbehaviour. Journal of School Psychology, 36(1), 7-27. doi: 10.1016/S0022-4405(97)87007-0.

Kingery, P. M., Coggeshall, M. B., \& Alford, A. A. (1998). Violence at School: Recent Evidence from four Nationality Surveys. Psychology in the Schools, 35(3), 247 - 258.

Kosovo Police, (2015). Yearly Report. Pristina. Retrieved from http://www.kosovopolice.com/repository/docs/Raporti_vjetor_i_pun\%C3\%ABs_s\%C3\%AB_Pol icis\%C3\%AB_s\%C3\%AB_Kosov\%C3\%ABs_2015_-_ANGLISHT.pdf.

Krasniqi, V., \& Osmani, T. (2012). Research on violence against children in schools in Kosovo. Unpublished report, Save the Children, Office in Kosovo. Pristina.

O'Keefe, M. (1997). Adolescents' exposure to community and school violence: Prevalence and behavioural correlates. Journal of Adolescent Health, 368-376. doi: 10.1016/S1054-139X(97)80131-0.

Pinheiro, P. S. (2006). World report on violence against children. Geneva. Published by the United Nations Secretary-General's Study on Violence against Children. Geneva, ATAR Roto Presse SA. 
Salzinger, S., Feldman, R. S., Stockhammer, T., \& Hood, J. (2002). An ecological framework for understanding risk for exposure to community violence and the effects of exposure on children and adolescents. Aggression and Violent Behavior, 7(5), 423-451.

Seitz, C., ed. (2011). Violence against children in schools: A regional analysis of lebanon, morocco and yemen. Save the Children Sweden. Retrieved from https://resourcecentre.savethechildren.net/node/5147/pdf/5147.pdf

Tait, L. A. D. (2004). School violence: A critical review of canadian and american studies (Unpublished master thesis). Simon Fraser University. Retrieved from: http://summit.sfu.ca/system/files/iritems1/7818/b39308054.pdf.

Tamo, A., \& Karaj. Th. (2006). Violence against Children in Albania. Tirana, $\backslash$. Retrieved from https://www.unicef.org/albania/Violence_against_children_in_Albania.pdf.

UNICEF, (2005). Research into violence against children in schools in Kosovo. Pristina, UNICEF Office in Kosovo. Retrieved from https://www.unicef.org/kosovoprogramme/kosovo_media_prot_011 